\title{
MuJeres haCIENDO CIUDAD: FLÂNEUSES Y LAS Sinsombrero'
}

\author{
Women Making City: Flâneuses and Las Sinsombrero
}

\section{Elia Torrecilla Patiño \\ elia.torrecilla@gmail.com \\ Universidad Politécnica de Valencia}

\section{RESUMEN:}

En este artículo se plantea un recorrido de la mano de algunas mujeres paseantes (flâneuses) que supieron afrontar las adversidades de un espacio público urbano destinado fundamentalmente a los hombres. Mujeres que a través de su presencia en las calles, supieron utilizar estrategias para trasgredir, mediante un uso creativo del cuerpo en el espacio, las normas sociales del momento; ése fue el caso de Las Sinsombrero.

A través de diferentes obras literarias, biografías, memorias y documentos fotográficos de escritoras y/o artistas, quedan registradas las experiencias y las limitaciones que las mujeres sufrieron durante sus paseos por la ciudad. Mujeres invisibilizadas, que debían permanecer en el entorno familiar y privado, pero que se lanzaron a un espacio público diseñado por y para el género masculino, mujeres que utilizaron su tiempo para ganar espacio. Mujeres que hicieron ciudad.

Palabras clave: mujer, ciudad, flâneuse, Las Sinsombrero, arte.

1. Este texto es resultado del Proyecto I+D: «Recuperación de prácticas pioneras del arte de acción de la vanguardia histórica española y su contribución a la historia de la performance europea». Agradecimientos al Ministerio de Economía y Competitividad (Proyecto ref. HAR2014-58869-P). 


\section{ABSTRACT:}

This article follows the steps of flâneuses who understood how to confront the adversities of an urban public space designed primarily for men. Through their presence on the streets and the creative use of their bodies in space, these women applied their strategies to violate the social norms of the day. These women were known as Las Sinsombrero (the hatless).

The women's experiences and the restrictions they faced during their walks through the city are recorded in literary works, biographies, memoirs and photographic documents by women writers and artists. Invisibilized women, who instead of conforming to the norm and remaining within the family and private space, broke out into a public space designed by and for men; women who used their time to win space; women who made the city.

KeYWORDs: woman, city, flâneuse, Las Sinsombrero, art.

\section{RESUM:}

En aquest article es planteja un recorregut de la mà d'algunes dones passejants (flâneuses) que van saber afrontar les adversitats d'un espai públic urbà destinat fonamentalment als homes. Dones, que a través de la seua presència als carrers, van saber utilitzar estratègies per transgredir, mitjançant un ús creatiu del cos en l'espai, les normes socials del moment; aquest va ser el cas de Las Sinsombrero.

A través de diferents obres literàries, biografies, memòries i documents fotogràfics d'escriptores i/o artistes, queden registrades les experiències i les limitacions que les dones van patir durant els seus passejos per la ciutat. Dones invisibilitzades, que havien de romandre en l'entorn familiar i privat, però que es van llançar a un espai públic dissenyat per i per al gènere masculí, dones que van utilitzar el seu temps per guanyar espai. Dones que van fer ciutat.

Paraules clau: dona, ciutat, flâneuse, Las Sinsombrero, art. 


\section{Introducción}

esde la aparición de la ciudad moderna, cuyo paradigma es el París del s. XIX recién remodelado por el barón Haussmann, son muchos los artistas que se han dedicado a tratar de comprender el nuevo fenómeno urbano, utilizando como práctica la actividad de caminar: inspirados por la figura del flâneur, las derivas situacionistas, el dada, el surrealismo, o el land art entre otros, hasta la práctica artística actual, el arte ha utilizado el caminar como experiencia socio-política para mostrar nuevas realidades posibles, así como forma de experimentar la ciudad en — y con— todos los sentidos. De ahí que el caminar se haya constituido como una metáfora del movimiento mental, físico y artístico.

Pasear y dejarse llevar por los ambientes de las calles que forman el laberinto urbano, sumergiéndose en un estado temporal caleidoscópico, es una actividad que supo desarrollar a la perfección un personaje (hombre), que es tan antiguo como la ciudad moderna; se trata de su propio resultado: el $f \hat{l}$ neur, una figura recuperada de la obra de Baudelaire y estudiada por Walter Benjamin en un proyecto que daría lugar a su obra póstuma, el Libro de los pasajes.

En él dedica un apartado a este caminante sin rumbo que permite explicar ciertos procesos sociales de la modernidad, porque la flânerie es una práctica que permite observar, evaluar la historia de la ciudad y detectar sus carencias, excesos e irregularidades; problemáticas como la escasa presencia de la mujer en el espacio público en una ciudad que comienza a dividir los espacios sociales principalmente entre el ámbito público y el privado, entre el interior y el exterior.

Tomando como paradigma la figura del flâneur y empleando la propia flânerie como metodología, poniendo el foco de atención en las calles transitadas, se hace visible la escasez de calles con nombre de mujer. Partiendo de esta experiencia, se propone un recorrido guiado por mujeres flâneuses que utilizaron su cuerpo para reivindicar un espacio y unos derechos a los que se les había negado el acceso y el disfrute. A través de estrategias propias de la práctica artística, ellas hicieron de la presencia en las calles una herramienta política y de transformación social, escribiendo la ciudad que ahora leemos. 


\section{Nota al pie}

En la actualidad, la flânerie - o el caminar como experiencia estéticadesvela los desajustes que existen en las calles de nuestras ciudades, que son reflejo de la sociedad en que vivimos; un acto tan sencillo como el de fijarse en el nombre de las calles por las que se pasea, pone de manifiesto la poca visibilidad que han tenido las mujeres en el espacio público, mostrando un fuerte desequilibrio histórico de género. Este hecho, evidencia que el planeamiento de las ciudades no se ha organizado en torno a los principios de libertad e igualdad, extendiéndose a todas las personas y grupos sociales, sino que se ha hecho respondiendo a las necesidades de un individuo universal: varón blanco, joven, con capacidad adquisitiva y heterosexual. De este modo, a través de los nombres de sus calles, se hace visible una sociedad notablemente desigual. $^{2}$

Con estos patrones, queda al margen otra ciudad formada por ciudadanos que no cumplen estos requisitos, que es la ciudad cotidiana donde habitan sujetos con una diversidad biológica, social, económica y cultural (Navarrete, 2016, p. 95), promoviendo una diferenciación social marcada de forma intensa por la desigualdad, la subordinación y la exclusión.

Culturalmente, el espacio siempre ha estado dividido entre el exterior y el interior; por lo público y lo privado, correspondiéndole a cada uno de ellos su propia audiencia: el espacio exterior y público ha sido destinado prin-

2. Calles transitadas durante un paseo realizado el 24 de julio de 2016 entre las 21:15 y las 22:40h.: Carrer de Palafox, Carabasses, En Gil, Baró de Cárcer, Editor Manuel Aguilar, Roger de Flor, Actor Riuelles, Hospital, Quevedo, Padilla, Gravador Selma, Sant Agustí, Guillem de Castro, Pare Jofré, Julio Antonio, Plaça d'Espanya, Gran Vía de Ramón y Cajal, Marvá, Albacete, Beat Gálvez, Jesús, Historiador Diago, Conca, Doctor Sanchis Sivera, Ángel Guimerá, Ferrán el Católic, Erudit Orellana, Calixt III, Literat Gabriel Miró, Sant Ignasi de Loiola, Azcárraga, Quart, Sant Jacint, Dr. Zamenhof, Passeig de la Petxina, Pont de les Glòries Valencianes, Menéndez Pidal, Mauro Guillén, Pla de la Saïdia, Guadalaviar, Pont dels Serrans, Blanquería, Serrans, Plaça de Manises, Comte d'Almodóvar, Batlia, Cavallers, Rellotge Vell, Juristes, Pujada del Toledà.

De todas las calles de Valencia, solamente el 10\% de las dedicadas a personas tienen nombre de mujer, y el $83 \%$ de las mujeres que aparecen son santas, vírgenes o nuestras señoras. Para más información: Llaneras, Kiko; Pérez Colomé, Jordi: «Ellos son doctores, ellas vírgenes y santas». El país digital [en línea]. 7 enero 2017. [fecha de consulta: 8 enero 2017]. Disponible en http://politica.elpais.com/politica/2017/01/06/ actualidad/1483666778_781495.html?id_externo_rsoc=FB_CC 
cipalmente a los hombres, encargados de representar las nuevas formas de experiencia pública, y el doméstico y privado el que ha sido asignado a las mujeres; una representación de la distribución sexuada del espacio de forma general, en las ciudades tradicionales.

\section{Mujeres a pie de calle}

Pasear por la calle, en soledad, sin rumbo fijo, dejándose llevar por la ensoñación y la fantasmagoría que producen las ciudades modernas, sin ninguna otra preocupación que el deleite estético, ha sido una actividad destinada fundamentalmente a los hombres; para ellos, pasear ha sido siempre un capricho, algo que dependía únicamente de su voluntad. Ello queda evidenciado y personificado a través de la figura del flâneur. En cambio, para la mujer, el paseo ha representado una conquista; ir de paseo ha supuesto para ella desprenderse de las imposiciones inherentes al patriarcado que la minoraba y la sigue minorando. Para la mujer, pasear ha sido un acto equívoco simplemente por resultar ocioso (Mina, 2014, p. 219-242).

Así como el flâneur se convirtió rápidamente en objeto de interés para autores como Fournel (1867), Benjamin (1940) o Hessel (1997) entre otros a partir de la primera mitad del s. XIX, el término flâneuse en tanto categoría histórica no había sido empleado por nadie, simplemente porque, al no ser posible, no existía. De hecho, Louis Huart (1842, p. 115), en un texto que excluye absolutamente a la mujer de la flânerie, ${ }^{3}$ aconsejaba:

Si no es razonable salir a dar un paseo en compañía de un amigo, es imposible dar un paseo en compañía de varios amigos: la flânerie no es solamente una caminata rápida. Las flâneries realizadas en compañía de una mujer deben ser evitadas. $^{4}$

3. Para conocer la relación que existe entre ciudad y creatividad a través de un paseo por diferentes ciudades cuyas calles han sido transitadas y vividas por flâneuses, ver: Elkin, Lauren: «Flâneuse. Women walk the city», Chatto\&Windows, 2016.

4. «S'il est déraisonnable de flaner en compagnie d'un ami, il est impossible de flaner en compagnie de plusieurs amis: la flânerie n'est plus qu'une rapide promenade. Les flâneries faites en compagnie d'une femme sont encore bien plus à éviter.» (Traducción propia). 
Podemos advertir a través de numerosos documentos sociológicos existentes, así como a través de los testimonios de diferentes autoras y pintoras del pasado, que al menos en el contexto europeo, la relación e interacción entre la mujer y la ciudad ha estado excesivamente limitada (Gómez Reus, 2005). Pero aunque la presencia de las mujeres en el espacio público estaba restringida, nadie logró apartarlas del todo de este ámbito y ocuparon el centro de las urbes, bien por obligaciones que vienen desde el espacio de lo privado y lo familiar como hacer la compra, o bien por la sencilla razón de dar un paseo, por puro placer. Porque sí.

En el primero de los casos, advertimos la presencia de una mujer «ama de casa», que es esposa y madre, cuidadora, y cuya mayor parte del tiempo está destinado al espacio íntimo, familiar y privado, básicamente destinado a la limpieza y al cuidado de la familia. Para esta mujer, el uso del espacio público sigue ligado al ámbito de lo familiar y se reduce a los espacios de las compras.

En esta actividad de comprar, aunque vinculada al entorno doméstico, el paseo se hacía posible en los grandes almacenes, esos nuevos espacios dedicados al consumo en los que se podía ver sin ser vista. Pero las deambulaciones que aquí tenían lugar no llegaban a gozar de la misma libertad que practicaba el flâneur, ya que a diferencia de éste, la flâneuse tenía un propósito de compra y consumo de bienes.

De la misma manera que al flâneur se le relaciona con la aparición de los pasajes, hay algunos estudios que tratan de relacionar los pasajes o los grandes almacenes - en la actualidad, centros comerciales - con un incremento de la presencia femenina en espacios públicos, ya que estos lugares rompen de alguna manera con la reclusión de la mujer en el hogar (Mina, 2005). Así, los primeros grandes almacenes serían espacios destinados a las mujeres, encargadas de las compras familiares, espacios cerrados pero por donde era posible deambular sin los peligros que acechaban las calles, además de contar con el consentimiento por parte del marido y la sociedad.

Esta distinción entre la ocupación del espacio público por parte de varios tipos de mujeres ya aparece en la obra El pintor de la vida moderna (1862), de Charles Baudelaire, una obra que recoge la esencia del flâneur como figura paradigmática de la experiencia urbana del París del s. XIX. En él, el poeta 
retrata a diversos tipos de mujeres pertenecientes a diferentes categorías sociales que ocupan el espacio público, actividad propia del flâneur, convertido en fisiologista y detective, que observa y describe a los distintos personajes que deambulan por las calles de la época.

En este sentido, en su texto «Mujeres y mujerzuelas», Baudelaire deja reflejada la diferenciación que existe entre dos tipos de mujeres que él observa en el espacio público. Por un lado, están las «mujeres que pasean por el parque acompañadas por sus maridos; mujeres respetables que visten con colores suaves y ropas sedosas que definen su clase social». Por otro lado, están esas «mujeres que son objeto de consumo sexual, que muestran sus cuerpos de manera abierta. En ellas, la ropa que visten hace resaltar su anatomía, revelando las formas que hay debajo» (2013, p. 51).

Baudelaire hace referencia a prostitutas, también llamadas «mujeres de la calle» y «mujeres de la vida». La primera de ellas es una mujer cuyo trabajo recibe el nombre de «hacer la calle». A este respecto Manuel Delgado (2006) plantea una reflexión sobre la gran diferencia que existe en la relación entre hombre y mujer con la calle como espacio físico y social. Una de estas desigualdades la encontramos en el empleo de la expresión «hombre público» que hace referencia a un personaje expuesto y visible, entregado a la crítica y opinión pública al que normalmente se identifica con el político o profesional; en cambio, una «mujer pública» designa a una mujer que es accesible a todos. Una prostituta que, sola ante la multitud, espera la compañía de un hombre. Entonces, cuando hablamos de la presencia en la calle, mientras el flâneur vagabundea, la mujer se prostituye.

Buck-Morss (1986, pp. 99-140) explica que aunque el acto de deambular que lleva a cabo la prostituta no tiene nada de la libertad artística que tenía para el flâneur, la prostituta no deja de ser una mujer paseante que puede convertirse en flâneuse al tener la posibilidad de observar la vida que tiene lugar en el espacio público. Para Benjamin, quien detectó tanto en la flânerie como en la prostitución rasgos de la modernidad social, cultural y económica, la prostitución encarna la transformación del mundo de las mercancías, pues la prostituta callejera deviene productora y mercancía al mismo tiempo. En este sentido y siguiendo la línea de Benjamin, BuckMorss comenta que la prostitución se convirtió en un fenómeno creciente 
durante la segunda mitad del s. XIX, haciendo del cuerpo de las mujeres una mercancía a quien la prostituta imita y de la que asume su atractivo: «Desear a la mujer-como-cosa que está a la moda y a la venta es desear el valor de cambio en sí, esto es, la esencia misma del capitalismo» (BuckMorss, 1986, p. 117). ${ }^{5}$

En ocasiones, las mujeres que simplemente buscaban disfrutar de un paseo por la ciudad y poder practicar la flânerie de una forma anónima y pasar desapercibidas, en definitiva, poder gozar de las mismas experiencias que el flâneur, tenían que recurrir a diferentes estrategias que les permitieran hacer uso de la libertad de caminar en soledad por las calles y dejarse atrapar por la fantasmagoría urbana. En su tesis, Hartmann (2004) habla sobre el uso que muchas mujeres hacían del disfraz. Cuando éstas adoptan la actitud de flâneuses y deciden salir a pasear, descubren que las calles son espacios que se encuentran muy ligados a los hombres. Por ello, resulta familiar el hecho de que no pocas mujeres tuvieran que recurrir a la vestimenta masculina para poder caminar por París libremente.

El travestismo intermitente capacitó a la mujeres a entrar en lugares generalmente prohibidos para ellas, y también ofreció la posibilidad de obtener oculta y completa libertad de movimiento [...]. Disfrazarse en términos de género proporcionaba un excitante sentido de invisibilidad, interrumpía el circuito de la objetivación [es decir, ser objeto del consumo visual del hombre heterosexual] y desviaba la atención que habitualmente despertaba la mujer sola en un lugar público. (Epstein Nord, 1995, p. 241)

En The Invisible Flâneuse (1995), Elizabeth Wilson reclama el papel real que la mujer tuvo en la sociedad europea del s. XIX y comenta que el disfraz hacía posible que la mujer pudiera disfrutar de sus paseos en solitario convirtiéndose en una «copia» del flâneur (hombre). De esta manera se liberaba de la mirada masculina y podía pasar desapercibida en el espacio público, porque en general, las mujeres no disfrutan del gozo que produce pasar inad-

5. Tanto Benjamin como Baudelaire ven el la figura de la prostituta el modelo paradigmático de la mercancía, pues la prostituta callejera deviene productora y mercancía al mismo tiempo. Benjamin detectó tanto en la flânerie como en la prostitución rasgos de la modernidad social, cultural y económica. 
vertidas entre la multitud: en el espacio urbano ellas no observan, sino que son observadas.

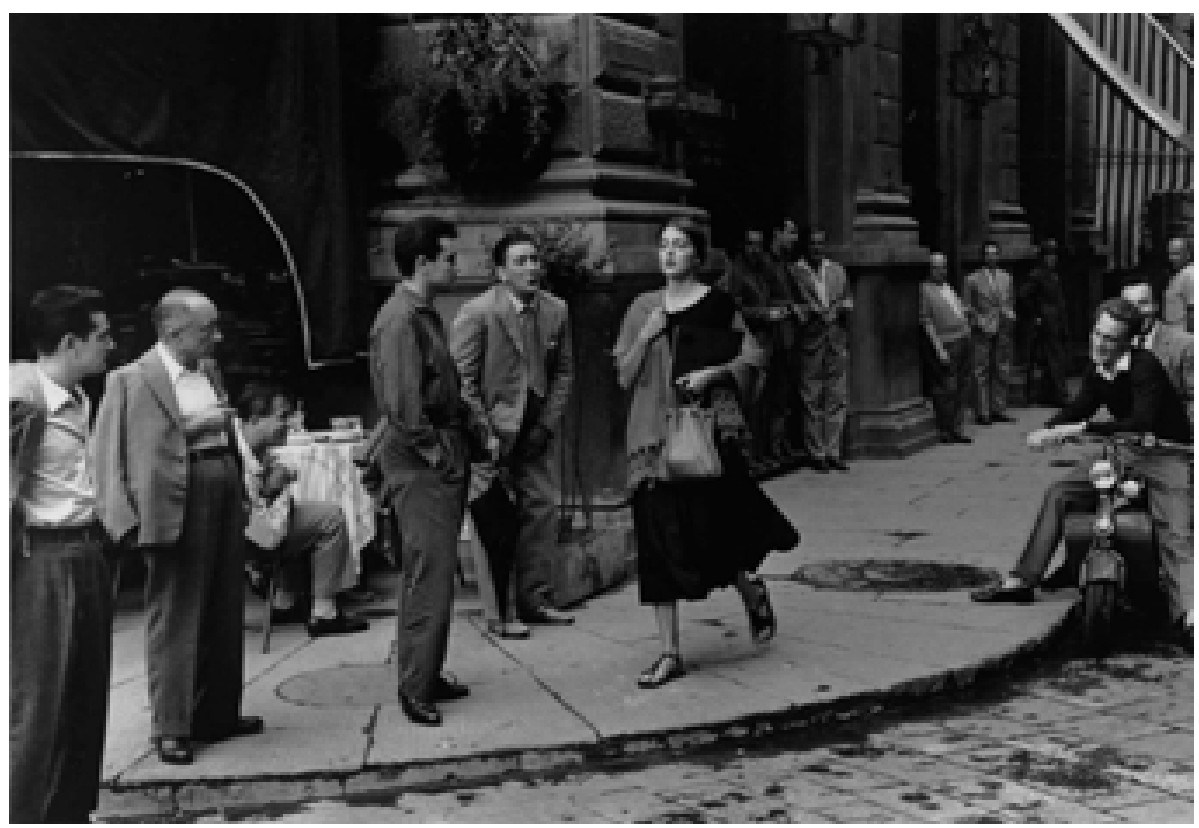

Figura 1. American Girl in Italy por Ruth Orkin, 1951. ${ }^{6}$

El propio Baudelaire explica que las mujeres son simples objetos que desfilan ante la mirada del flâneur, y en este sentido, recurrir al disfraz se trata de una solución temporal y de algún modo performativa.

Para las mujeres burguesas, ir a la ciudad y mezclarse con las multitudes de composición social mixta no era sólo peligroso por ser poco familiar, sino porque era moralmente peligroso [...] Los espacios públicos eran oficialmente el terreno de y para los hombres; para las mujeres entrar en él conllevaba inimaginables riesgos [...] Para las mujeres, los espacios públicos podían ser un lugar

6. Imagen obtenida en Elkin, Lauren. «A tribute to female flâneurs: the women who reclaimed our city streets». The guardian, 20 julio 2016. Recuperado de: https://www. theguardian.com/cities/2016/jul/29/female-flâneur-women-reclaim-streets?CMP=share_btn_fb

De la misma autora, ver: Elkin, Lauren. flâneuse. Women walk the city, Chatto\&Windows, 2016, para conocer la relación que existe entre ciudad y creatividad a través de un paseo por diferentes ciudades cuyas calles han sido transitadas y vividas por flâneuses. 
donde una perdía su virtud, se ensuciaba; la salida al espacio público y la idea de la desgracia estaban íntimamente alineadas. ${ }^{7}$ (Pollock, 1988, p. 69)

Entre el juego del disfraz y la moda, aparecen las mujeres dandys y, aunque para muchos autores son y deben ser hombres (para Benjamin un dandy es siempre un flâneur, no una flâneuse), existen referencias (Durán, 2009) que muestran la existencia de mujeres dandys consagradas. Mujeres como Mademoiselle de Montpensier, la Condesa Dash, la Condesa de Merteuil y Mathilde de La Mole supieron construirse a ellas mismas a través del atuendo, suprimiendo la división de géneros y haciendo de sus vidas una verdadera obra de arte.

En la influyente obra de Janet Wolff The Invisible Flâneuse: Women and the Literature of Modernity (1991), la autora profundiza en la incompatibilidad que la presencia y el pasear por el espacio público tiene para las mujeres pintoras o escritoras, y al detectar la ausencia de un equivalente femenino del flâneur, propone la figura de la «flâneuse invisible». Wolff explica que los estudios más destacados sobre la modernidad, realizados por Baudelaire, Simmel o más recientemente, por Richard Sennett, asocian el fenómeno de la modernidad al espacio público, obviando así la experiencia de las mujeres en este periodo histórico. De este modo, la figura del flâneur en toda la literatura moderna solamente puede ser encarnada por un hombre. La invisibilidad de la flâneuse es retomada por Griselda Pollock, quien revisa el movimiento impresionista desde la óptica del feminismo.

Una manera de justificar la presencia femenina en las calles durante el siglo XIX era a través de la dedicación de las mujeres al arte, especialmente dentro del movimiento impresionista, que fue uno de los primeros grupos de artistas que contaron con un notable número de mujeres entre ellos. En su texto Modernity and the Spaces of Feminity, Pollock (1988) realiza un estudio sobre cómo las diferencias del uso y el acceso al espacio público influyeron

7. «For bourgeois women, going into town mingling with crowds of mixed social composition was not only frightening because it became increasingly unfamiliar, but because it was morally dangerous [...]. The public space was officially the realm of and for men; for women to enter it entailed unforeseen risks [...]. For women, the public spaces thus construed were where one risked losing one s virtue, dirtying oneself; going out in public and the idea of disgrace were closely allied». 
en la carrera profesional de pintoras impresionistas como Mary Cassat o Berthe Morrisot, e investiga las disparidades entre la representación del espacio en las mujeres impresionistas y los pintores varones. En los cuadros de estos últimos es común la aparición de bares, cafés o burdeles en los que las mujeres aparecen como objetos de deseo; en cambio, en las pinturas de las mujeres impresionistas, aparecen sobre todo interiores domésticos como el salón o el dormitorio, ámbitos no urbanos como el jardín de la villa de verano o espacios fronterizos como terrazas, ventanas o balcones.

Como explica Trasforini:

La mujer artista que se acerca a la escena moderna de la metrópolis desafía a las figuras masculinas más laureadas de la modernidad: el flâneur de Baudelaire, el extranjero blasé de Simmel, el dandy de Lord Brummel y Oscar Wilde. En los espacios de la modernidad como lugares profundamente marcados por el género, ella es la aspirante flâneuse, una huésped no atendida y poco bienvenida que genera desconcierto. Es la mujer nueva que en la naciente cultura de masas está en sintonía con las libertades prometidas por la modernidad, pero está en contradicción con las restricciones de una sociedad que está rediseñando las fronteras del género. (2009, p. 21)

Frente a las restricciones de acceso al espacio público que han sufrido las mujeres durante el siglo XIX en occidente, ellas han ido desarrollando una serie de tácticas para hacer un uso creativo del espacio público. En este sentido, Virginia Woolf, quien hacía un uso de las calles como un acto de investigación, y gracias a la cual reflejar el paseo en la literatura se volvió un hecho relevante, propone indagar en los escritos autobiográficos de mujeres, con el fin de profundizar en cómo a lo largo de la historia han relatado su experiencia como mujeres que viven el espacio urbano, su experiencia como flâneuses (Cuvardic, 2002, p. 57).

Woolf (2014, p. 17) denominó a la experiencia de conocer la ciudad a través del callejeo «street haunting» o ruta callejera, en un ensayo homónimo que recoge la ensoñación a través de un paseo, en el que la propia autora es transformada por el ambiente de la calle:

Cuando salimos de casa en una hermosa tarde entre las cuatro y las seis, nos despojamos del yo por el que nuestros amigos nos conocen y nos convertimos en 
parte de ese vasto ejército republicano de peatones anónimos, cuya proximidad resulta tan grata al abandonar la soledad de nuestra casa.

De una forma general, desde el siglo XVIII, las mujeres que más han tenido acceso libre al paseo han sido las pertenecientes a la clase alta y especialmente las solteras, aunque sus caminatas siguieran estando más bien sujetas al ámbito de lo privado al desarrollarse dentro de sus posesiones, como en jardines privados o durante sus paseos en coche. Muchas de estas mujeres de clase alta, en ocasiones realizaban viajes a diferentes lugares del mundo por donde paseaban, aunque quizá se trataba de un desplazamiento más sujeto al turismo.

En sus escritos, Woolf empleaba de forma repetida el término «impedimento» para referirse a las dificultades que se les presentan a las mujeres a la hora de escribir, expresión que también utilizaba como metonimia para las artistas que trabajan en otros campos, especialmente en las artes plásticas y visuales. Resulta revelador que el «impedimento», etimológicamente, «lo que está en el lugar de los pies», parece ser el conjunto de obstáculos que dificultan o imposibilitan el movimiento en las mujeres (Trasforini, 2009, p. 157).

Resulta también significativo que durante el siglo XIX y principios del XX, las mujeres debieran llevar sombrero, como si quisieran esconderlas o como forma de evitar que dejaran volar sus pensamientos, algo que por otro lado se ofrecía como ventaja para deambular por la ciudad disfrutando de cierto anonimato. Durante el siglo XIX en Francia era un deber que las damas llevaran cubiertas sus cabezas, ya fuera con un sombrero o con velo, como signo de elegancia y clase social. En cambio, las prostitutas tenían prohibido llevar cualquier elemento que cubriera sus cabezas.

\section{Mujeres de paseo y sin sombrero}

Hubo un tiempo en el que un grupo de flâneuses, de mujeres artistas, luchadoras, dandys... de la vanguardia española habitaban las calles del Madrid de los años 20. Ellas fueron el primer grupo de mujeres artistas que se introdujo sin complejos en el circuito artístico, pertenecientes a la Generación del 27 
(1023-1936), a la que la Guerra Civil puso fin. Ellas eran María Zambrano, Rosa Chacel, Josefina de la Torre, Ernestina de Charpourcín, María Blanchard, Remedios Varo, Ángeles Santos, Rosa García Ascot, Zenobia Campubrí, Maruja Mallo, Concha Méndez, Margarita Manso, Carmen Conde, Marga Gil-Roësset o María Teresa León, entre otras. Mujeres de gran talento que con su obra influyeron de forma determinante en el arte y pensamiento español (y también desde el exilio) de la época. Este grupo de mujeres se conoce como «Las Sinsombrero», ${ }^{7}$ a las que los muchachos arrojaban piedras por resistirse a llevar sombrero en la vía pública.

A finales de la década de los años veinte, Maruja Mallo regresó a España y salió a dar un paseo por la madrileña Puerta del Sol junto con sus amigos Margarita Manso, Dalí y García Lorca. Llevaban sombrero, como todo el mundo por aquel entonces, al comienzo de su paseo, pero en un momento dado decidieron continuar la caminata sin él. Este acto resultó tan escandaloso que los transeúntes comenzaron a insultarles e incluso a apedrearlos. En palabras de Maruja Mallo:

Íbamos Federico, Dalí, Margarita Manso y yo. Hoy puede parecer increíble, pero ocurrió tal y como te lo cuento. Llegamos a la Puerta del Sol y un grupo de gente comenzó a tirarnos piedras mientras nos gritaban a grito pelado: «Maricones, maricones». Y nosotros venga a correr para que no nos dieran. Y dice Federico: «Lo peor es que no lo somos». Y Dalí: «Sí, sí: lo somos...». (Ferris, 2004, pp. 82-85)

Desde entonces, ir por la calle con la cabeza descubierta se convirtió en un acto de transgresión y modernidad, sobre todo por parte de ellas, quienes estaban obligadas a llevar puesto el sombrero incluso dentro del teatro. Una actitud pionera que se prolongó hacia los años 30 con un movimiento generalizado llamado Sinsombrerismo.

Este acto de quitarse el sombrero queda también apuntado en las memorias de Concha Méndez:

La noche de mi descubrimiento en el Palacio de Cristal había conocido a la pintora Maruja Mallo y empecé a salir con ella por Madrid. Íbamos por los barrios bajos, o por los altos, y fue entonces que inauguramos un gesto tan simple como quitarse el sombrero. (Ulacia Altoaguirre, 1990, p. 43) 


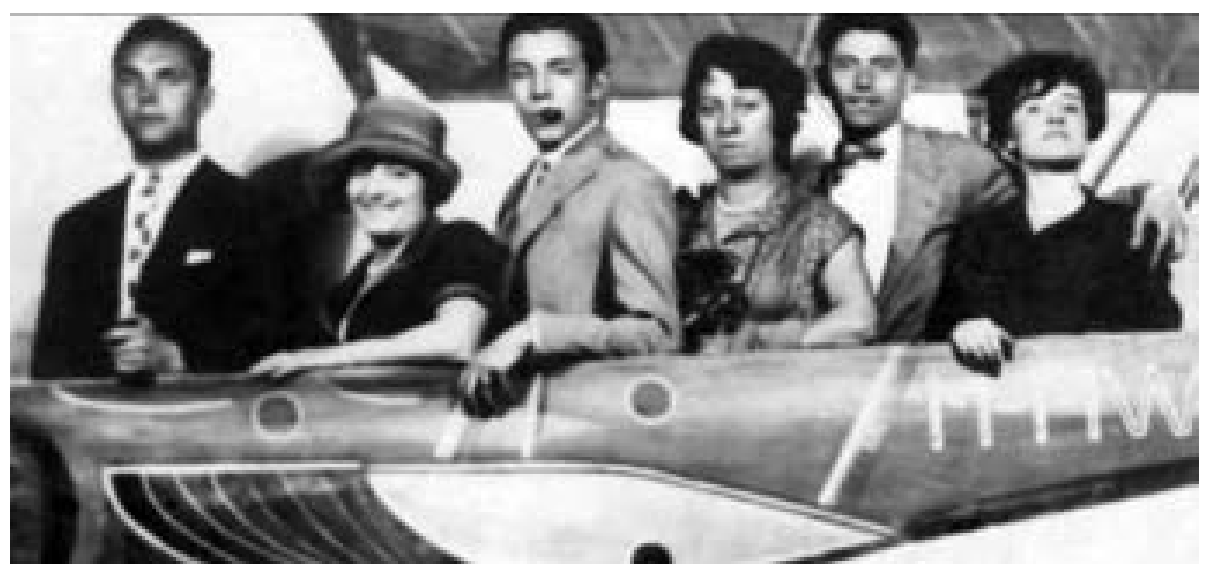

Figura 2. De izquierda a derecha: no identificado, Rosa Chacel, no identificado, Concha Méndez, Gregorio Prieto y Maruja Mallo. ${ }^{8}$

También en sus memorias quedan registradas numerosas alusiones a su presencia en el espacio público, donde relata sus paseos con Maruja Mallo haciendo evidente que ellas mismas se convirtieron en flâneuses como una estrategia para convertirse en artistas:

[...] íbamos al Museo del Prado y a las conferencias de Eugenio d'Ors, a las verbenas y a los barrios bajos de Madrid. Nos paseábamos para ver aquellos personajes tan pintorescos que pasaban a nuestro lado iluminados por los faroles de la calle.

Estaba prohibido que las mujeres entraran a las tabernas; y nosotras, para protestar, nos pegábamos a los ventanales a mirar lo que pasaba dentro. Los domingos por la tarde íbamos a la estación del Norte, a ver a la gente que va y que llega, a los viajeros con sus despedidas y los trenes. (Ulacia Altoaguirre, 1990, pp. 227-228)

Si «el hombre de la multitud» observaba el espectáculo desde el interior de un café londinense hacia fuera, estas mujeres sin sombrero lo hacían desde

8. Soria Olmedo, A. (ed.) (2009). La Generación del 27. ¿Aquel momento ya es una leyenda? Madrid: Residencia de Estudiantes, p. 101. 
el exterior hacia adentro como un acto de enfrentamiento hacia una realidad basada en las diferencias de género.

Estas artistas de la vanguardia histórica española se encontraron con grandes dificultades para tener un protagonismo social en la vida pública de su tiempo. Las mujeres tenían prohibido el acceso a monasterios de religiosos, un impedimento que dio lugar a la improvisación de una especie de happening: cuando Maruja Mallo y Margarita Manso quisieron entrar, en la primavera de 1926, al monasterio de Santo Domingo de Silos a escuchar el canto gregoriano de los monjes, no les dejaron pasar. Para lograrlo, lo resolvieron cambiando su ropa por los pantalones y la chaqueta de Dalí y Lorca que las acompañaban, y ocultándose el pelo con unas gorras. Respecto al hecho de evadir las prohibiciones de género con creatividad, Maruja Mallo declaró posteriormente: «Fuimos las primeras impulsoras del travestismo a la inversa» (Molina, 2008). Así, estas estrategias empleadas para salir a disfrutar de un paseo solitario por las calles de la época, como la de recurrir al disfraz, pueden ser leídas en clave de performance o happenings.

La forma en que Mallo y su amiga decidieron afirmar su independencia como mujeres modernas y su vocación de artistas de vanguardia fue, según reflejan estos ejemplos, la creación y exhibición (performance) de una nueva identidad social, femenina, que quedaba al margen de restricciones sociales como las normas de género o clase.

En el análisis que Kakie Urch realiza sobre la flâneuse, indica que una mujer que se construye a sí misma en público es una artista, porque «el yo performativo es una obra de arte, artificio e identidad». De este modo, el acto por parte de estas artistas de quitarse el sombrero podría leerse como una actitud propia de la modernidad, incluso podría aproximarse al dandismo al investigar la relación que existe entre el cuerpo y el espacio como una acción estrechamente vinculada a la visibilización de la mujer en el espacio público; de hecho, las memorias de Méndez indican que Mallo imaginaba las excursiones sin sombrero como una especie de humorística. Acciones que trataban de experimentar nuevas formas de practicar la vida cotidiana, porque la actitud de la modernidad, la actitud dandificada, busca otras vías para hablar en el espacio de lo público (Durán, 2009, p. 641). 
De esta manera, Maruja Mallo y Margarita Manso llevan a cabo una singular aventura de flâneuses por el Madrid moderno de los años veinte que supone el inicio de una nueva identidad social para dos mujeres artistas. Cabe destacar la conexión que Maruja Mallo tenía, aparte de la pintura, con el arte de acción, concretamente dentro del género de la fotografía (Molina, 2008); una parte importante de su universo creador, como muestran varios reportajes fotográficos, como el realizado en la Isla de Pascua (Chile) junto a su amigo Pablo Neruda, cubierta por exuberantes algas marinas, convertida en una sirena de las profundidades marinas.

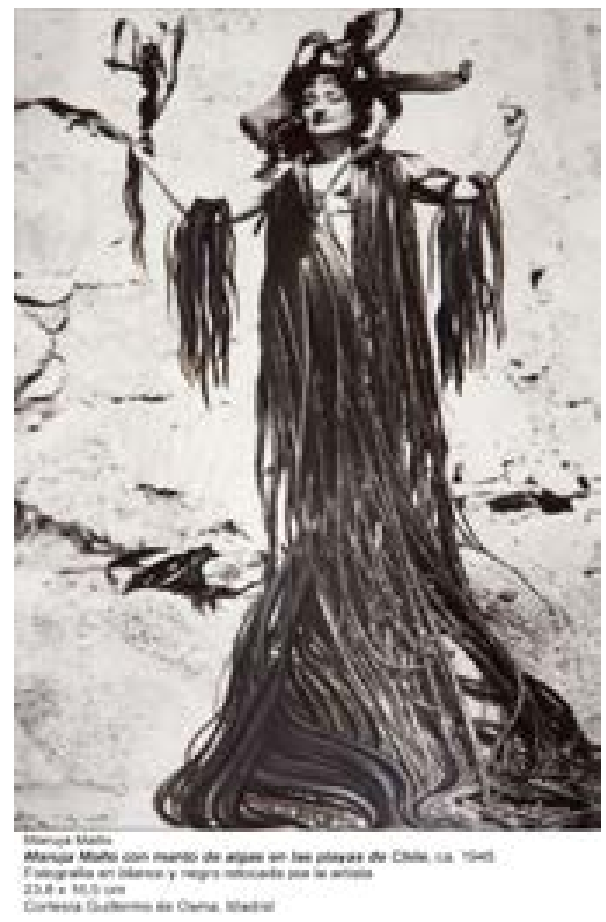

Figura 3. Maruja Mallo con manto de algas, Chile, ca. 1945. Fotografía retocada por la artista. ${ }^{9}$

También la poetisa y atleta Concha Méndez simboliza la imagen emergente de la mujer moderna urbana que asume la ciudad como espacio privilegiado de la modernidad y como espacio artístico que se escribe y desde donde se escribe, como refleja el poema Paisaje en el que la figura del hablante lírico se representa como una flâneuse que recorre la ciudad desde la pantalla del

9. Imagen obtenida en: Catálogo de la exposición Naturalezas vivas, Galería Guillermo de Osma y Fundación Caixa Galicia, 2002. 
tranvía sin ningún tipo de contaminación sentimental: «Paisaje urbano. / Mi frente, / junto al cristal del tranvía» (Méndez, 1928).

\section{A modo de conclusión: «Ciudad» es nombre de mujer}

Es probable que las palabras ciudad y mujer puedan parecer contradictorias, porque como comentábamos al principio, a la mujer siempre se la ha relacionado más con el ámbito de lo privado — espacio de invisibilización-, en contraste con el espacio público, visible y destinado al hombre. Pero a pesar de estas restricciones y otras adversidades, muchas mujeres supieron cómo evadir las dificultades, las limitaciones y las prohibiciones del tiempo que les tocó vivir, y salieron a la calle para caminar, ver, escuchar y respirar el aire de la ciudad. Haciendo uso de un lenguaje artístico y literario reivindicaron su derecho a ser y estar en el espacio público, como es el caso de Maruja Mallo o Concha Méndez, que lucharon por hacerse visibles en el escenario urbano a través de sus happenings y haciendo uso del disfraz.

La actividad de la flânerie ha sido también empleada como herramienta de análisis del espacio urbano en ámbitos como la arquitectura y el urbanismo. En este sentido, la experiencia y observaciones aportadas por muchas mujeres que se lanzaron a caminar por las calles, como Jane Jacobs (2011), entre otras, fueron determinantes en muchos planteamientos formulados, proponiendo un urbanismo incluyente y con vías seguras para todos los ciudadanos por igual, porque el espacio tiene género y el género tiene espacio. El modelo espacial de gran parte de las ciudades responde a las demandas de una economía basada en la división tradicional de lo masculino y lo femenino, lo público y lo privado y en un modelo familiar tradicional.

La participación de las mujeres y su presencia en las calles ha sido determinante para un cambio drástico en el ámbito del espacio público, de la ciudad, que es la polis, lo político. Y aunque gracias a ellas se ha hecho más posible la presencia y visibilidad de la mujer en este ámbito, las calles siguen siendo espacios de constante violencia para las mujeres, por lo que el camino a conquistar es todavía largo. 
Para que la mujer pueda disfrutar de esas caminatas anónimas y callejear sin rumbo, primero ha de salir a la calle para reivindicar su derecho a la ciudad. Reclamar igualdad, democracia, libertades y justicia social, porque pasear en soledad por las calles de la ciudad es un ejercicio de libertad. Las manifestaciones de las mujeres, a partir de su presencia en el espacio público, de sus acciones artísticas, literarias, poéticas... las empoderaron e hicieron más visibles.

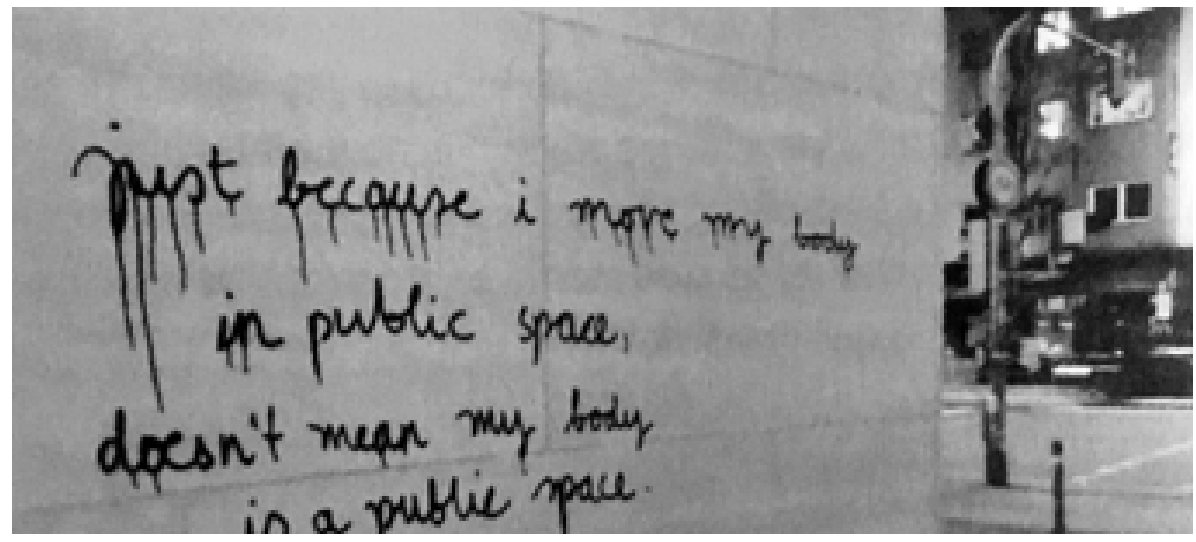

Figura 4. «Sólo porque yo desplace mi cuerpo en el espacio público no significa que mi cuerpo sea un espacio público». ${ }^{10}$

El derecho a la ciudad implica el derecho a serflâneuse, el derecho a pasear y poder perderse sin miedo, sin la presión que ejerce el sentirse observada y juzgada; disfrutar del aire de la ciudad, de la libertad, dando rienda suelta a los pensamientos y discurrir sin encontrar impedimentos por unas calles con nombre de mujer. Como decía Walter Benjamin, caminar sin rumbo, deambular y perderse en la multitud es la forma de empezar a encontrar nuevos rumbos.

10. Imagen en: Smith, Phil (2015). Walking's new movement. Axminster: Triarchy Press, p. 16. (Traducción propia.) 


\section{Referencias}

Baudelaire, C. (2013). El pintor de la vida moderna. Madrid: Taurus.

Benjamin, W. (2007). Libro de los pasajes. Edición de Rolf Tiedemann. Madrid: Akal.

Buck-Morss, S. (1986). «The flâneur, the Sandwichman and the Whore: The Politics of Loitering». New German Critique. No. 39 (Fall).

Calles Moreno, J. M. (2014). «Concha Méndez, la seducción de una escritora en la modernidad literaria». En: Salir del camino. Creación y seducciones feministas, Dossiers Feministes, 18.

Cuvardic García, D. (2002). El flâneur en las prácticas culturales, el costumbrismo y el modernismo. París: Éditions Publibook.

Delgado, M. (2006). «Mujeres de la vida». El País. Recuperado de: http:// elpais.com/diario/2006/01/10/catalunya/1136858843_850215.html

Durán Hernández-Mora, G. (2009). Dandysmo y contragénero. La artista dandy de entreguerras: Baronesa Elsa von Freytag-Loringhoven, Djuna Barnes, Florine Stettheimer, Romaine Brooks. (Tesis doctoral inédita.) Valencia: Universidad Politécnica de Valencia.

— (2015). «Silenciosas voces públicas: "Las Sinsombrero" por el Madrid de los veinte». ¡CHUM, CHUM, PIM, PAM, PUM, OLÉ! Pioneros del Arte Sonoro en España, de Cervantes a las Vanguardias. Valencia: Universidad Politécnica de Valencia.

EPSTEIn NoRD, D. (1995). Walking the Victorian Streets. Women, Representation, and the City. Ithaca: Cornell University Press.

Ferris, J. L. (2004). Maruja Mallo: La gran transgresora del 27. Madrid: Temas de Hoy.

Gómez Reus, T. (2005). «Habitar/escribir/conquistar el espacio». Feminismo/s. Revista del Centro de Estudios sobre la mujer de la Universidad de Alicante, número 5.

Hartmann, M. (2004). Technologies and Utopias: The ciberflaneur and the experience of «Being Online». (Tesis doctoral inédita.) London: University of Westminster.

Hessel, F. (1997). Paseos por Berlín. Madrid: Tecnos.

Huart, L. (1842). Physiologie du flâneur. Paris: Aubert-Lavigne.

JACoBs, J. (2011). Muerte y vida de las grandes ciudades. Madrid: Capitán Swing.

Méndez Cuesta, C. (1928). Surtidor. Madrid: Imprenta Argis. 
Mina, J. (2014). El dilema de Proust o el paseo de los sabios. Un ensayo sobre el paseo en la historia y la literatura universales. Córdoba: Editorial Berenice.

Molina Alarcón, M. (2008). «La performance española avant la lettre: del ramonismo al postismo (1915-1945)». Chámalle X. IV Xornadas de Arte de Acción da Facultade de Belas Artes da Universidade de Vigo. Vigo: Publicaciones de la Universidad de Vigo.

NAVARREte, C. (2016). «La ciudad: un lugar a conquistar para la diversidad». En G. Cortés, José Miguel (dir). Perdidos en la ciudad. La vida urbana en las colecciones del IVAM. Valencia: La colección del IVAM, Dos, 2016.

Pollock, G. (1988). «Modernity and the Spaces of Femininity». Vision and Difference: Femininity, Feminism and the Histories of Art. London and New York: Routledge.

Trasforini, M. A. (2009). Bajo el signo de las artistas. Mujeres, profesiones de arte y modernidad. Valencia: Universidad de Valencia.

Ulacia Altoaguirre, P. (2003). Concha Méndez. Memorias habladas, memorias armadas. Madrid: Mondadori 1990, pág. 51. Citado en: Kirkpatrick, Susan. Mujer, modernismo y vanguardia en España (18981931). Madrid: Cátedra.

Woolf, V. (2014). «Ruta callejera». En Paseos por Londres. La línea de horizonte edicion. 